\title{
The Empirical Research on Shanxi Province of the Poverty Level Change of Urban Residents
}

\author{
Qingqing Bai \\ School of Xingzhi school, Xi'an Institute of Finance and Economics University, Xi'an 710038, China. \\ baiqingqing.good@163.com
}

Keywords: Shaanxi Province, Urban residents, Poverty level, Change.

\begin{abstract}
Since the 1990s, with the acceleration of urbanization, the problem of urban poverty has increasingly become a prominent issue in Shaanxi's social and economic system. Resolving urban poverty in a reasonable manner is a matter of economic development, and it is also a social issue. Fair and just demands. Anti-poverty has long been the focus of attention of the Chinese government, academia, and the public. In recent years, with the implementation and development of poverty alleviation work, the achievements made by Shaanxi Province in poverty alleviation work have attracted worldwide attention. Relatively speaking, the problem of urban poverty has not yet attracted the attention of relevant parties. through comparative analysis. The experience of anti-poverty in cities and towns in developed and developing countries puts forward to speed up the development of urbanization in Shaanxi Province, improve the social security system and the development of non-governmental organizations in poverty alleviation, etc. to study the changes in the urban residents' poverty in Shaanxi Province.
\end{abstract}

\section{Introduction}

At present, the academic community is consistent with the understanding of the scale of urban poverty, problems and their consequences, the reform and establishment of a market economy, the relationship between a sound social security system, and how to treat and treat urban poverty. It is particularly noteworthy that previous studies have failed to link the urban poor to urbanization.

The low level of urbanization in Shaanxi Province as the western region has become a major obstacle to the long-term stable development of the economy. the process of urbanization must be accelerated in the future economic development. The essence of urbanization is the process of rural population migration to cities. In the process of urbanization in Shaanxi Province, a large number of rural residents will enter the city [1]. A new poverty class may appear in the city. Coupled with the poverty-stricken stratum in the city, the poverty problem in the city will become more prominent, which will become the long-term development process of Shaanxi Province in the future. One of the major bottlenecks. This increasingly serious problem, in turn, will hinder the acceleration of the urbanization process. From the final result, if we do not speed up the process of urbanization, it will seriously limit the space and potential of economic development, as well as the fundamental transformation of economic and social structure, thus losing the best opportunity to solve the problem of unemployment and poverty, which makes Shaanxi Province Urbanization faces a dilemma [2].

\subsection{Urban Poverty is Mainly a Relative Poverty}

People have a process of understanding poverty. At first, understanding poverty is absolute poverty. The so-called absolute poverty means that the actual income obtained, the consumption materials it has, and the services it receives cannot reach the minimum amount necessary to maintain its basic survival needs. Relative poverty means that although income can meet and exceed the need to maintain survival and basic development, it is still at a lower standard of living compared with the level of social and economic development in a certain period [3]. Relative poverty largely reflects the situation of social distribution inequality. At present, urban poverty in China is mainly manifested as relative poverty. With the widening of the income gap between urban residents, the urban minimum 
income family lives very hard. Because they are often faced with problems such as employment and health, their lives are very low. The standard is relative to the rural poor [4].

\subsection{Urban Poverty Has a Great Impact on the Lives of Urban Residents}

Poverty has a great impact on the poor themselves and their families. First of all, because of poverty, their living standards are very low. Their income can only meet the most basic living needs. They face great difficulties in education, health care and housing, etc. Education relates to the human capital of the poor and their relationship. The level of investment in human capital to the children, housing and medical care are related to the physical health of the poor themselves and their families, and a healthy body is the most basic guarantee of poverty alleviation. In the current life of the urban poor, on the one hand, children cannot drop out of school because they cannot afford the cost of education for their children [5]. This results in the children's inferior status in the future life competition, which may lead to the International transmission of poverty and, on the other hand, to illness. I can't get my job because treating illness makes it harder for my already impoverished life to fall into a cycle of poverty. These two aspects are absolutely the main trend of life for poor families, and they are also the main breakthroughs of urban anti-poverty.

\subsection{Urban Poverty Affects the Development and Stability of the Entire Society}

The expansion of the scale of urban poverty and the deepening of its degree are the deviations from the goal of common prosperity. Further expansion of the gap between the rich and the poor will lead to the emergence of many social problems and affect the stability of the entire society [6]. On the one hand, the poor will fight against individuals and groups, especially organized protests, such as organized demonstrations and collective petitions. On the other hand, the issue of poverty has become an important issue in the political life of today's world. Poverty groups have also become a force that cannot be ignored in the political life of all countries. They will influence the direction of politics.

In addition, the existence of a poverty problem will lead to changes in the social structure. Once a relatively stable poor class occurs in society, the original hierarchical structure and system will change. In short, the problem of urban poverty will affect the integration and order of the entire society, which ultimately leads to a lack of motivation in this social development and undermines the sustainable development of society.

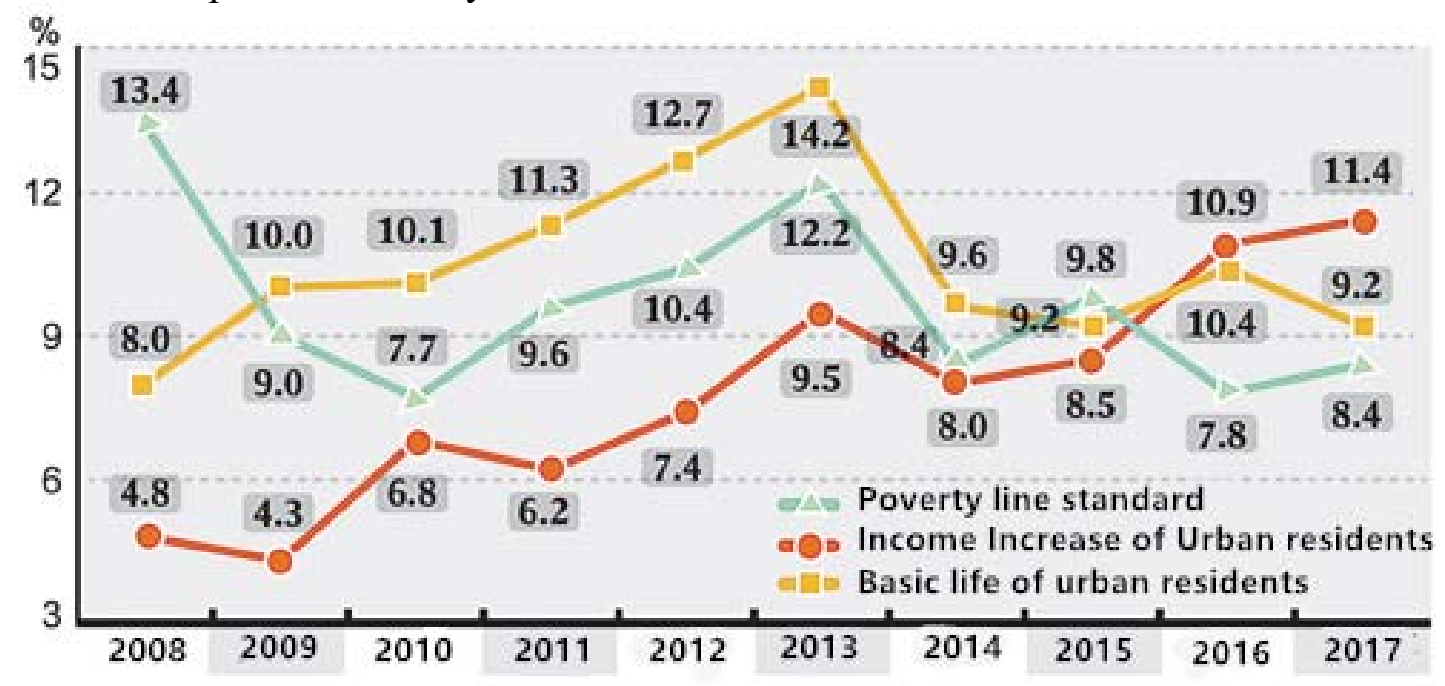

Fig 1. The income curve of residents in Shaanxi Province

\section{Analysis of Causes of Poverty-stricken Population in the Process of Urbanization in Shaanxi Province}

\subsection{The Causal Model of China's Urban Poverty Study}

The current problem of urban poverty in our country occurs under a specific socioeconomic condition. One of the key aspects of our research is to conduct an explanatory study of urban poverty, 
that is, to explore the causes of poverty. Among them, we need to analyze and summarize the main variables that lead to the current urban poverty and analyze the institutional and policy socioeconomic roots behind these variables. There are many causes of poverty, both personal and social. Especially in the process of social and economic changes, the phenomenon of group differentiation is often more prominent. There are always some groups that can hardly share the fruits of socioeconomic development with other groups, and therefore fall into relative poverty. In terms of personal and family reasons, a person's physical characteristics psychological reasons, educational level, etc., or family Various factors will affect poverty in varying degrees. In any poverty phenomenon, we may see that individual or family factors play a role. From the perspective of various microscopic factors, we can often further analyze the deeper socioeconomic root causes.

\subsection{The Socioeconomic Reasons of Urban Poverty in the Process of Urbanization in Shaanxi Province}

When the analysis from the macro-social level leads to the economic and social causes of the current urban poverty problem in Shaanxi Province, we first notice the economic and social transformation that has taken place in China in recent years. At the same time as economic growth, the income gap between residents has continued to expand, indicating that economic growth is a prerequisite but not a sufficient condition for the elimination of poverty. Because economic growth is one of the ways to eradicate poverty, it is in terms of long-term trends: in the short term or at a certain period, although economic growth has increased overall income, the coefficient has rapidly expanded, weakening the poverty-stricken population. Wealth growth capabilities and opportunities.

\section{(1) Widening Income Gap Among Urban Residents}

The coefficient of urban residents in Shaanxi was 0.15 at the beginning of reform and opening up in 1978. After the 1990s, the income gap widened rapidly. By 2004, the coefficient had reached 0.46, exceeding the warning line of 0.45 . It shows that the gap between the rich and the poor has grown and the social stratification has become clearer.

Judging from another measure of the income gap of all social strata, the proportion of $40 \%$ of low-income households in urban residents in Shaanxi Province has been declining, and $60 \%$ of middle- and high-income households have been on an upward trend, indicating that the growth rate of high-income households is very high. Faster than low-income households, the relative gap between rich and poor continues to widen.

\section{(2) Widening Income Gap in the Industry}

With economic development, industrial restructuring, and unequal competition conditions in various industries, the income levels of various industries will inevitably change, and the types of industries that urban residents engage in will become an important factor affecting their income. According to statistics, the newly added impoverished urban population in Shaanxi Province is mainly concentrated in loss-making and bankruptcy enterprises. In Shaanxi Province, due to the low wage income, the proportion of manufacturing and commerce accounts for far more than other industries, and the average income of these two industries is just close to the minimum standard of living.

\section{(3) Regional Income Gap Expansion}

Since the reform and opening up, the income levels of urban residents in various regions of Shaanxi Province have significantly increased, but the income growth rate has been different, which has led to an increase in the income gap between regions. The income gap between regions is mainly due to the unbalanced regional economic development. The urban poor population in Shaanxi Province is mainly concentrated in northern Shaanxi and southern Shaanxi, which is closely related to the level of economic development.

\section{The Problem of Unemployment and Urban Poverty in the Process of Urbanization in Shaanxi Province}

In economic growth, not only does the distribution of income affect urban poverty, but there is also a high degree of positive correlation between unemployment and poverty. In general, the 
unemployment rate should tend to decline and the incidence of poverty will decrease as a result of economic growth. However, under the background of Shaanxi's economic restructuring and economic restructuring, the relationship between economic growth and unemployment has become very special. From the statistical point of view, since the 1990s, Shaanxi's economy has been maintaining a trend of gradual increase, but at the same time the registered unemployment rate in urban areas has been rising all the way, causing an increase in the incidence of urban poverty. The Lagging Behind of the New Type Social Security System and the Problem of the Urban Poverty Population in the Process of Urbanization in Shaanxi Province

\subsection{The Main Problems Existing in the Shaanxi Social Security System}

(1) There is a large gap between old-age income and expenditure, and there is a tendency of increasing year by year. This undoubtedly increases provincial-level financial risks. In 2002, the basic old-age pension was 3.95 billion yuan, and the expenditure was 5.05 billion yuan. The difference in revenue and expenditure was mainly filled by the central government transfer payment.

(2) The level of basic pension is low. In 1995, Shaanxi Province established a regular adjustment mechanism for basic pensions for retired employees of enterprises and made annual adjustments to the basic old-age pension for retirees. The current problems are: early retirement, low salary, late retirement, and high salary.

(3) New problems in the reform of state-owned enterprises. More prominent issues include the issue of old-age insurance for retired employees who have bought out seniority in enterprise restructuring and one-time pension settlement. Dispose of the old-age insurance relationship and the new insured enterprises to make up for the arrears since the implementation of the individual payment system.

(4) The coverage of industrial injury and maternity insurance is small, and the rate of participation is low. Shaanxi's industrial injury insurance and maternity insurance are still at the primary stage of social co-ordination, and their policies and technical strengths are strong. In addition, there are no legislation at this stage, and some private and township and township enterprises do not participate in work-related injury insurance for various reasons.

(5) The basic management is weak and publicity is not in place. Due to the limitation of the number and quality of insurance workers and the lack of in-depth propaganda work, many employees do not understand the social insurance policies; employees' awareness of participation in insurance is not strong, resulting in low participation rates and low collection rates.

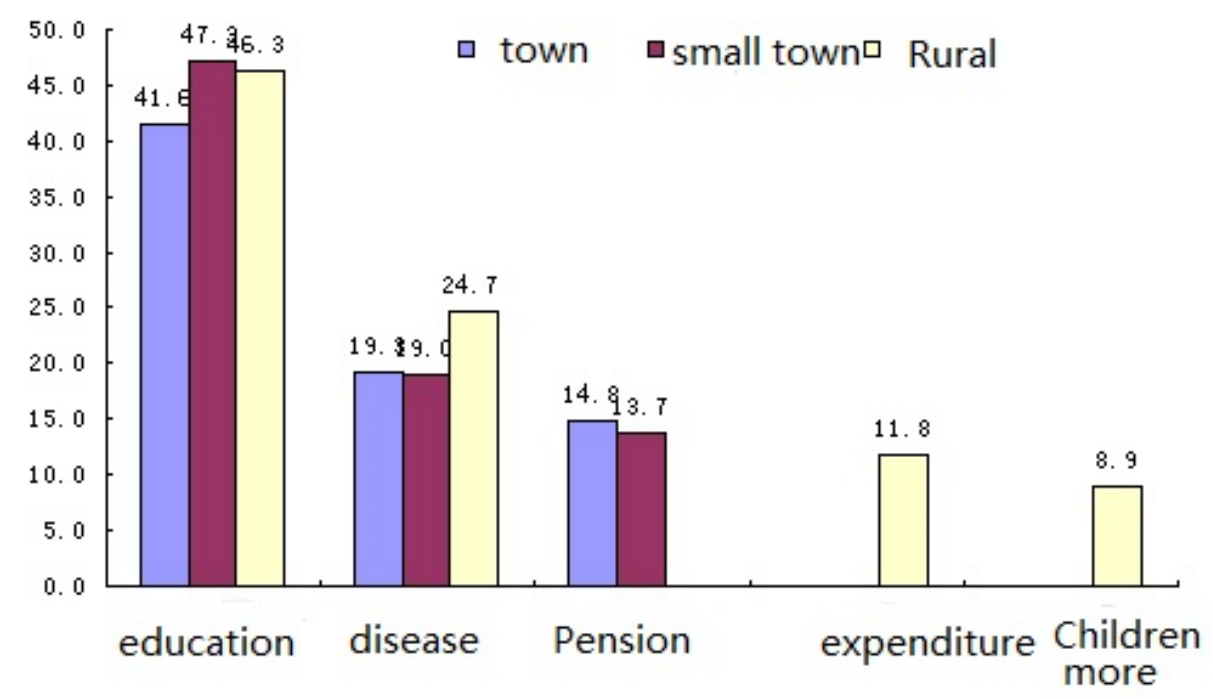

Fig 2. the Causes of poverty for urban residents

\subsection{The Impact of Lagging Social Security System in Shaanxi Province on Urban Poverty and Poor Population}

(1) Too low social insurance coverage reduces the protection of social security for low-income people. Especially vulnerable groups that are not covered are vulnerable to poverty. The low rate of 
participation greatly reduces the residents' ability to withstand risks and increases their chances of falling into poverty.

(2) Too low contribution rates make the various safeguard items virtually useless, guarantee services cannot be implemented, and safeguard measures cannot be fulfilled. The results of the survey conducted by the Shaanxi Provincial Department of Labor and Social Security show that the proportion of medical insurance, unemployment insurance and pension insurance paid in full and on time is not too high, which will inevitably affect the living conditions of the poor and their families.

\subsection{The Floating Population and Urban Poverty in the Process of Urbanization in Shaanxi Province}

In the process of urbanization, a large number of rural people have moved to cities. One fact that cannot be avoided is that the problem of urban poverty has become more complicated and serious. In fact, currently the composition of the poor population in Shaanxi Province has shown a pattern of "three yuans" standing side by side, namely, the rural poor population, the urban poor population, and the impoverished people who have flowed between urban and rural areas. The majority of the rural poor have been transferred from rural areas to urban areas. Their social status, status, and living conditions have not changed fundamentally. Instead, they have only changed the existence of poverty, that is, the transformation from a rural poor population to poverty in urban and rural areas. Population, and become a "new three without" poverty group living in the city without fixed work, no fixed income, no fixed place of residence.

\section{Research on Anti-Poverty in Cities and Towns in Shaanxi Province}

\subsection{Raise the Quality of the Urban Poor and Create Conditions for Them to Participate in Poverty Alleviation}

The poor have historically been regarded as vulnerable groups and have been rejected by society. Many rights have been denied or cannot be realized at all. There is a basic precondition for the poor to truly participate in poverty alleviation activities. That is, the poor must have certain qualities. The most important thing for the poor to participate in poverty alleviation is to find out how they can play their role and grant them the basic ability to get rid of poverty, that is, empowerment. Basic ability includes general ability and specific ability, general ability refers to literacy, basic management skills (such as bookkeeping, records), family health, family planning, etc. Specific capabilities include production skills of agriculture, forestry, animal husbandry, and fisheries, processing savings, marketing skills. When designing the anti-poverty mechanism, we must combine the characteristics of urban poverty in Shaanxi Province and the level of economic development in Shaanxi Province to discuss long-term plans.

\subsection{Increase Government Support for Urban Anti-Poverty}

Anti-poverty action is a kind of public behavior and it is also an economic and social function of the government. The government's support for urban anti-poverty is mainly concentrated in three aspects. First, financial support. Financial support is the core of government support. The number of urban poor people in Shaanxi Province is relatively large. If there is no adequate funding support from the central government and local governments, even the best anti-poverty system will not be implemented. Although non-governmental organizations and international organizations can provide some financial support, they are temporary and limited in number. From the perspective of the world's anti-poverty practice, the country's financial support is an important guarantee for the success of anti-poverty and a prerequisite for ensuring the sustainability of anti-poverty action. At the same time, the government needs to use macroeconomic controls to redistribute resources, eliminate unfair social distribution, and increase the assets of poor people so as to increase their ability to resist risks, because the number of assets owned by the poor directly affects their ability to escape poverty. Second, theoretical research supports this. From the perspective of our country's anti-poverty process, our government's support has always been centered in rural areas, and cities are almost vacuum. With the acceleration of the process of industrialization and urbanization in our country, the problem of urban poverty has become increasingly prominent and has become a major problem affecting the 
economic and social development of cities and towns. The problem of urban poverty in our country appears to be later than that of the western countries. Therefore, the theoretical research on this aspect has lagged behind. In order to effectively solve the problem of urban poverty, the government has the responsibility to organize relevant experts to conduct research and formulate effective anti-poverty mechanisms in cities and towns. Third, management support. Strengthen the management of all kinds of anti-poverty issues in cities and towns, especially strengthen the management of poverty alleviation funds, increase the efficiency of fund use, and reduce waste.

\subsection{Improve the Relevant Legislation of Social Security}

We must have enough understanding of the positive role of legislation in anti-poverty: Only through relevant legislation can we define the rights and obligations of governments at all levels and the poor in the form of laws, and strictly implement the poverty alleviation actions in accordance with the regulations in order to standardize poverty alleviation. Behaviors, reducing various wastes, and safeguarding the legitimate rights and interests of the poor can effectively punish all kinds of violations. From the perspective of China's anti-poverty practice, due to the lack of relevant laws and regulations in China, the arbitrariness of poverty-relief actions is relatively large, resulting in an increase in the cost of poverty alleviation and a reduction in the effectiveness of poverty alleviation. The most obvious manifestation is that the poverty alleviation funds have not been issued in full and on time. In the hands of the poor, they were misappropriated and privately divided.

\section{Conclusion}

By predicting the incidence of poverty and its relationship with related variables, this paper analyzes the causes of urban poverty and grasps the evolution trend of poverty, providing a policy basis for Shaanxi Province to manage urban poverty and avoid the deterioration of urban poverty. However, taking into account the long-term and inevitability of poverty, although economic development can be reduced until the elimination of absolute poverty, it can never eliminate its relatively poor population; the existence of vulnerable groups is a long-term common social phenomenon.

\section{Acknowledgments}

This article is the 2017 Higher Education Program of the Shaanxi Provincial Education Science Program: An Empirical Study of the Changes in Urban Poverty Level in Shaanxi Province Project Number: 17JK0969.

\section{References}

[1]. Xue Haitao, et al. Problems and Countermeasures in Economic Transformation of Mining Cities in Shaanxi Province. Economics and Management. Vol. 7 (2005) No. 11, p. 112-118.

[2]. Wan Wei, et al. Study on the problem of urban poor population in China. Coastal Enterprises and Technology. Vol. 9 (2005) No. 12, p. 321-325.

[3]. Chen Xiaoping, Lu Xinyu, et al. The relationship between the process of urbanization in China and the urban poor. Coastal Enterprises and Technology. Vol. 2 (2005) No. 10, p. 335-338.

[4]. Chen Qiuyu Zhang Xiao, et al. Review of the Connotation and Subject of Urban Managemen. China's Private Economy and Technology. Vol. 5 (2005) No. 4, p.213-216.

[5]. Jiang Peigang, et al. The current situation and development of tourism in Shaanxi 1. Economic Development of Western China. Vol. 12 (2005) No. 4, p.267-272.

[6]. Jing Baihao Yu Huifang, et al. Transformation of Resource-based Cities and Institutional Innovation. Economic Forum. Vol. 6 (2005) No. 9, p.37-45. 